\title{
Analysis of current situation and reform ideas of humanistic quality education of private college students
}

\author{
Zhang Yunling \\ Xi'an International University, Xi’An, 710077, China
}

Keywords: private college students; humanistic quality; construction analysis

\begin{abstract}
This article from the connotation of humanistic quality education and to explore the value of rational analysis of the status quo of private college students, expounds the students' Humanistic Quality Education in Colleges and universities in private colleges, presenting the status quo of humanistic quality of students in Colleges and universities of our country private colleges, and from students, schools and social aspects analyzes the causes of humanistic quality China's education of private college students about the defect. Put forward some countermeasures on strengthening and improving students' Humanistic Quality Education in Colleges and universities in private colleges, namely the humanistic quality education innovation channels,improve the quality of school education system, embodies the humanistic quality education of the students in private colleges college age Four aspects, such as introducing advanced experience of humanistic quality education abroad, have provided new ideas and approaches for the reform of humanistic quality education in Colleges and Universities.
\end{abstract}

\section{Introduction}

With the rapid development of science and technology and the loss of humanistic spirit, the world began to re-examine the important value of humanistic quality education. To improve college students humanistic quality has become the focus of higher education reform in the world.20 at the end of the century, requests the school through moral education, to enhance students sense of social responsibility, only strengthen the humanities education, improve students moral level, in order to solve the human face of war crime, poverty and other disasters. So foreign to the humanistic quality education of university students of non Constant attention, a lot of practice worth learning. However, from the relevant research, their basic connotation of humanistic quality education of college students and the main structure of new exploration in today's conditions, but not enough, at the same time for the analysis of the causes of the problems are very difficult to adapt to the Chinese state, thus providing reference is quite limited.

To strengthen the humanistic quality education of college students, is the free and comprehensive development requirements, requirements for the comprehensive quality of higher labor and time, is one of the direction of the reform of higher education; promote the humanistic quality education in private colleges, it is necessary to develop socialist builders and successors with noble personality. Only provide professional education and knowledge cannot provide wisdom education, cognition, emotion, volition, healthy and comprehensive development, rationally play their intelligence, training mainly depends on the humanistic quality. At present, graduates of the historical mission, social responsibility, moral consciousness, innovation ability, language expression and writing ability, self Know that the interpersonal relationship and the spirit of cooperation and other aspects of the poor performance, it is the lack of humanistic quality education or ineffective. To effectively solve this problem, we must make a comprehensive study on the humanistic quality education of college students nowadays situation, understanding and analysis, the only way to find the cause of problems, the to put forward a comprehensive, system, feasible solutions, truly achieve the goal of quality education. 


\section{Private university students' Humanistic Quality}

Most of the students think that writing skills, practical ability, psychological ability, interpersonal relationship ability is very important for the future development of their own, but in how to improve their thinking ability and improve little by what way. Rarely active understanding of humanistic knowledge, even for some lectures on humanities, rarely take the initiative in their common problems. They think that this kind of scholarship certificate, scores, practical things to win for themselves a better future. Together, the humanistic quality is relatively weak mainly in the following aspects.

(1) lack of humanistic knowledge

We found that college students spend less time reading books in the humanities investigation. Some students even some middle school reading books are not read, they hand holding computer training books or teachers qualification certificates and other materials of various books occupy most of them learning time for other humanities books to reading. Support this view there is a famous university students had a humanistic knowledge test, all questions are for the middle school history, language, politics and other basic knowledge, there are $68 \%$ of the students failed.

(2) The humanistic spirit has been perplexed

In the market economy and the opening of the shock wave, pragmatism is clearly on the rise in University, in the choice of professional knowledge and occupation selection, so there is an obvious tendency of quick success, students' excessive pursuit of money and material, the pursuit of ideal spirit has a spiritual vacuum.

Our society is in the transition period, the great prosperity of socialist culture, people's outlook on life, values in the reconstruction period. But the development of commodity economy not to people's moral setback for the price. The market economy emphasizes competition, pay attention to personality, but not to abandon the collective spirit, honest and trustworthy, weak and poor. Social virtues. To promote individuality, not to harm the interests of others as the premise, to comply with the social order, safeguarding social public security as a basis.

Although the lack of a group of high moral quality of students, but more and more uncivilized phenomenon. Such as class noise, tardiness, cheating, littering, trample on the lawn. The phenomenon of moral decline is also reflected in the part of College Students' collective sense, only personal struggle, do not speak together. Some students think that a waste of time to participate in collective activities and energy, indifferent to others, to the collective, the state and society the lack of sense of responsibility.

\section{Analysis of the reasons for the weak humanistic quality of College Students}

(1) Social influence

Have a strong impact on the campus of the university students "cannot meet the needs of the market economy, the increasingly severe employment situation, the employment pressure increases. The students choose a professional, no longer consider personal ideals, but by the professional employment and development prospects for the scale. College life is taking employment as a" baton ", put a lot of time in the study of professional knowledge and obtain the qualification certificate, certificate of honor, ignoring the cultivation of humanistic quality. On the other hand, influence the development of science and technology, but also make a lot of college students" materialized ", that is to take over the pursuit of material enjoyment, and gradually neglected spiritual pursuit.

(2) School guidance

Students early professional, more specialized courses, less humanities courses. Most of the students believe that learning courses occupy most of the time, are somewhat powerless, no time to take into account other activities. Due to the strong background of private universities, culture comprehensive schools lack of some lectures and community activities, the students' participation enthusiasm is not high. On the one hand is because there is no time, partly because the activities become a mere formality, not to stimulate the interest of the students. Due to the increasingly fierce competition among schools, focus on teachers, school size, the number of press effect index, in 
practice the lack of response The cultural construction of the measures, the quality of education as a teaching work without embellishment, the quality of education to implement from the classroom to the outside, to the life of the students living in three-dimensional space by learning. In addition, the consciousness of teachers' humanistic quality education also affects the cultivation of students' Humanities Quality and enhance the teachers' personality charm, such as sense of responsibility, dedication to the shaping of students' humanistic quality training plays a subtle role.

(3) Individual thoughts

And elementary education, higher education is to let the students in the university study and life formed and established their own outlook on life, world outlook and values, and many students just entered the University at that moment, it was a lot of thoughts, they even have a chance to establish their own "threeoutlooks" imperceptibly accepted the existing ideas, this leads to some students' actual weight, light spirit; heavy eyes, light in the long run, the formation of a misunderstanding, the humanistic quality is far better than the scores, scholarship, various certificate to have their own significance, to improve the humanistic quality consciousness is weak. In addition, the unemployment rate for college graduates is year by year This rise, the severe forms of employment for the students a lot of pressure, the pressure forced them to pay more attention to their professional ability, especially for students majoring in science and engineering, they abandoned the original not much of the humanities courses to strengthen the study of professional courses.

\section{The problems of humanistic quality of College Students}

This paper summarizes the following aspects of the problems of the humanistic quality of private college students:

(1) the ideological and political quality is not high, the lack of social responsibility and historical mission, for social progress, national prosperity, national rejuvenation and other issues not enough attention, little interest. Life values emphasis on personal value, personality value, self realization, is conducive to mobilize the enthusiasm of the personality and play, but also easy to the value of the balance bias.

(2) the moral concept is weak, the basic civilization accomplishment is not high, the collectivism idea, the public civilized behavior is very deficient. The moral nihilism has certain market

(3) the ability to control social life and adapt to social life is poor, the ability to recognize and regulate interpersonal relationships, public relations is poor, and there are more confusions in social life

(4) lack of knowledge in history, society, politics and culture is a serious problem. Most students are not familiar with basic social and political knowledge, history and cultural common knowledge, they do not understand it, and they do not even know it at all.

(5) aesthetic taste, taste is not high, aesthetic ability is poor, the lack of standards for beauty, the connotation and nature of the correct understanding and accurate grasp.

(6) poor psychological endurance, poor psychological quality of honor and disgrace, and worse frustration. It is easy to go to extremes in the face of setbacks, adversities, and blows.

(7) without innovation consciousness and creativity, to a great extent, it is still the study mode and tradition of reading books and reading books.

(8) initiative is poor, truly ambitious, lofty ideals of the students is few, mediocre, mostly follow the common psychological tendency of ignorance and even contempt. Noble has a certain universality.

\section{The reasons for the problems of humanistic quality education in private universities}

(1) the misleading of traditional ideas

For a long time, especially for the university to know and understand the functions and responsibilities of private college, many people put it on imparting knowledge and skills training, in a sense, the existing university education tend to become a professional education. And the limitation of professional education is one that has been repeatedly proved by practice fact. Due to 
too much emphasis on professional education and skills education, students lack the most basic of the humanities and social science knowledge, go to the society, it is difficult to adapt to the social life, especially it is difficult to adapt to the modern social life. This point in the private college students in performance is particularly prominent.

(2) misunderstanding of ideological knowledge

Due to the prevailing idea tendency of education professionals, caused some misunderstanding of college education. Its main performance is: one is the weight of Polytechnic Education in private colleges in light literature and history. Due to the formation of students' specific skills and knowledge, to enable students to form a specific operation and practice ability, and people literature due to the longer period of internalization and the transformation process, not immediate, therefore not taken seriously. Some traditional subjects and long-term discipline and even fell to the two position. No one shows any interest in, emerge of itself and perish of itself is light skills theory. Many subjects only pay attention to skill training, but ignore the theoretical accomplishment. Only by whether students have mastered certain or some practical ability, but do not see The really know the truth, to grasp the inherent laws, the result is not conducive to the sustainable development of the students. The three is light weight fraction. University continues from primary school to high school examination system, a measure of the level of the students is still the standard scores. Students in order to test only by rote, and did not understand the problem in finding problems, analyzing problems and solving problems ability has increased.

(3) the utilitarian tendency of training mode

Since the reform and opening up, China's market economic system, as a social economic base, the market economy that plays the decisive role in the social life in a certain sense. Therefore, the value orientation of market economy influenced social value orientation. And the reality of the market economy is the main economic benefits as the dominant value orientation. So, can bring direct economic benefits, consciously and unconsciously become higher education especially the target of science education and the pursuit of economic benefits. And to evaluate the training standards for private college and education quality will inevitably lead to one sidedness of the personality of the subject of education. The current college of science, The separation of workers, in addition to a small number of universities, the vast majority of private university disciplines monotonous, a serious lack of science and social science and technology conditions of mutual penetration, lack of Humanities and social sciences education content, channel, carrier and atmosphere, and the reality of middle school science and medicine of the future is bound to be an accountant. Economist, designers, engineers, doctors, have to create economic benefits. Proficiency in a particular line of "practical" has become the biggest feature of the University at the same time, quick success has become the main drawbacks of university development.

(4) the educational system, the operation mechanism and even the curriculum are unreasonable

Because of these factors, but also resulted in China's higher education system, operation mechanism and course system is not reasonable. Our university has long formed a unified enrollment, unified system, unified teaching plan and syllabus, especially the unified school year system and the compulsory system, the undergraduate students of colleges and universities in private colleges training until graduate training the lack of humanistic quality education leeway. Plus the value orientation of utilitarianism, private college curriculum is too one-sided, the science and technology curriculum of excessive pressure, resulting in a serious lack of private college students' all-round development of autonomy.

(5) formalization and utilitarianism of campus culture

Private colleges and universities as the professional has some limitations, the campus culture often become the important channel and carrier of humanistic quality education and edification. But the current campus culture, mainly by some young cadre school in group or leading private universities. Colleges and universities presided over the understanding limit makes some schools only pay attention to the challenge cup competition the content of science and technology, personal development for young cadres performance requirements, and also makes some people only pay attention to the form and influence of campus culture, but does not pay attention to actual effect. 
Therefore the important role of Colleges of private college campus culture is difficult to play its influence and humanistic quality education.

\section{Strengthen the thought and implementation path of humanistic quality education in private universities}

(1) raise awareness, change ideas, and lay down the correct and scientific ideological foundation and prerequisite for quality education

The development of human society for the advancement of modern science and technology at the same time, also call for the return of humanistic quality, calls for construction of scientific exploration and cultivation of humanistic spirit. To improve the students' humanistic quality education ideological change is the forerunner of humanities education, should strive to quality education and the Humanities and social science and culture quality education combined gradually; establish financial knowledge, cultivating ability, improve the quality as one of the educational ideas and teaching mode, in the new perspective to better understand the overall development of education policy.

We must strengthen the whole society especially the leadership of scientific quality education of ideological education, establish talents should possess comprehensive quality, integrity, comprehensive development of the basic connotation of the concept of the whole society, especially the college students and staff recognize that humanistic quality education is not only for the improvement of moral cultivation of Contemporary College Students, an important means of cultivation theory and culture, is the objective requirement of the all-round development of people, but also the development of the national economy and the important means and conditions for the overall progress of the society, is the inevitable requirement of social development. Therefore, to the comprehensive development of human freedom from the height from the height of social progress, from improving the national quality Highly aware of its importance.

(2) the quality education must have reliable organizational guarantee and implementation rules. Colleges private colleges should according to their own characteristics, establish and improve the humanistic quality education management system and operation mechanism, overall planning, comprehensive coordination, and constantly improve the level of management, so as to ensure the school humanities quality education effectively, rapid and healthy development. At the same time in the system, operation mechanism, specific measures should put the humanistic quality education into the whole university organization system, operation mechanism and regulations rules, so it has reliable organizational guarantee and follow the rules. Only in this way can make the humanistic quality education into practice, practical results .

(3) to ensure the effectiveness and purpose of campus culture, and to give full play to its humanistic quality education and the important role of edification.

Campus culture is an important part of school quality education, it has the unique value of education and other disciplines teaching area, for Polytechnic Colleges and its role is more important and obvious. Therefore, in content and form, must fully consider the limitations of the psychological characteristics of University of science and technology education and private colleges, for private college students exist in the aspect of cultural quality defects, follow the law of education and the law of the psychological development of students, respect the subjectivity and selectivity principle of students, encourage students to participate actively, bold and creative performance, and on the basis of the popularity, as far as possible to meet the students' desire to improve.

Campus culture must overcome the formalization and utilitarian tendency, to show the behavior, and effectively carry out campus cultural activities. According to the construction of campus culture, let students imperceptibly improve aesthetic accomplishment in practice, the pursuit of beauty gradually internalized to conscious behavior. At the same time to adhere to the popularization and improvement of the principle of combining multiple channel, multi-level campus culture activities should be combined with the theme of education, the education of the situation, traditional festivals and anniversaries to carry out large-scale cultural activities; students regularly organize the contents 
of health, elegant style, the theme of novel humanities education seminars; according to the students' interest in extracurricular small organization Group or student organizations, to provide a platform for exchanges and enhance students; vigorously carry out community activities, science and technology, culture and Art Festival and other cultural activities on campus, let the students in private colleges and universities by multi angle, in the rich and colorful campus life in the multi-level, many aspects of humanistic quality edification.

\section{References}

[1] Yuan Zhenguo, research on policy support system for quality education. Shandong Education Press, 2004 (10).

[2] Wang Yingjie, <2005: China's education development report: development of higher education, problems and countermeasures. Beijing Normal University press, 2005 (12).

[3] Pan Maoyuan, new century higher education research series, multidisciplinary perspectives on higher education research, Shanghai Education Press, 2001 (9).

[4] Mei Baoshu, $<<$ aesthetic education and quality education facing the new century $>>$, people's press, 2004 (6).

[5] Wang Yingjie, the development and reform of American higher education, people's education press, 2002 (1).

[6] Foreign Affairs Bureau of Chinese Academy of Social Sciences, humanities and Social Sciences in the United States, social science literature press, 2001. 